\title{
Cambios en la superficie sembrada de palma aceitera en el cantón de Osa, Puntarenas. Período 2014-2018
}

\section{Changes in the area cultivated with oil palm in the canton of Osa, Puntarenas. 2014-2018 period}

\author{
Denis Mauricio Salas-González ${ }^{1}$ \\ Universidad Nacional, Costa Rica
}

\begin{abstract}
Resumen
El cultivo de palma aceitera muestra un acelerado crecimiento a nivel mundial. Según datos oficiales, solo en la región latinoamericana se evidencia un crecimiento del $150,8 \%$ en el área cultivada de palma de aceite al pasar de 443000 hectáreas en 2001 a 1111000 hectáreas sembradas en 2014, de las cuales 818000 se encontraban en etapa productiva aportando cerca del $6 \%$ del aceite de palma producido en el mundo (González, 2016). Estas plantaciones han impactado los paisajes tropicales por la disminución de la vegetación natural, pastos o por el reemplazo de otros cultivos. La expansión del cultivo de palma de aceite aumentó en Costa Rica y de acuerdo con la tendencia de los últimos años, seguirá en aumento. En los últimos años se han realizado censos y encuestas agropecuarias que muestran el crecimiento general, pero no detallan las áreas geográficas donde se da ese crecimiento y el consecuente impacto a la dinámica natural de las áreas cultivadas, información clave para los procesos de ordenamiento territorial regional y local que tenemos en el país. Por tal motivo, los objetivos de esta investigación fueron: analizar el cambio en la superficie sembrada con palma aceitera en el cantón de Osa, provincia de Puntarenas en el periodo 2014-2018 y evaluar la expansión del cultivo de palma aceitera en los distritos del cantón. Para esto, se analizaron datos de instituciones gubernamentales y se identificaron y digitalizaron las plantaciones de palma aceitera de los seis distritos del cantón de Osa.
\end{abstract}

Palabras clave: cambio de uso, SIG, palma aceitera, frontera agrícola, Zona Sur.

1 Licenciado en Geografía. Universidad Nacional, Costa Rica. Investigador del Instituto Regional de Estudios en Sustancias Tóxicas (IRET). Correo electrónico: denis.salas.gonzalez@una.cr https://orcid. org/0000-0003-2390-7177 


\begin{abstract}
Oil palm cultivation shows accelerated growth worldwide. According to official data, the Latin American region alone has seen $150.8 \%$ growth of area destined to oil palm cultivation, expanding from 443,000 hectares in 2001 to 1,111,000 hectares in 2014, of which 818,000 hectares were in the harvesting stage whereby contributing to approximately $6 \%$ of worldwide palm oil production (González, 2016). Oil palm plantations have impacted tropical landscapes by the decrease of natural vegetation, pastures or by replacing other crops. Oil palm cultivation increased in Costa Rica and, according to the trend of recent years, will continue to rise. In recent years, agricultural censuses and surveys have been carried out that show the general growth of cultivated land but omit to detail the geographical areas of expansion, nor depict the consequent impact on the natural dynamics of the cultivated area; both aspects constitute key information for regional and local territorial planning processes taking place in the country. Thus, the objectives of the present research were: to analyze the change in oil palm cultivated area in the canton of Osa, province of Puntarenas in the 2014-2018 period, and evaluate the expansion of oil palm cultivation in the districts of the canton. Accordingly, data from government institutions were analyzed and the oil palm plantations of the six districts of the Osa canton were identified and digitized.
\end{abstract}

Keywords: Land-use change; GIS; Oil palm; Agricultural frontier; Costa Rica's Southern Zone.

\title{
Introducción
}

La demanda mundial de cultivos básicos, forrajeros y biocombustibles aumenta a un ritmo sin precedentes y se refleja en el incremento del cultivo agrícola. Este incremento agrícola y expansión de monocultivos tienen consecuencias ambientales graves para los ecosistemas tropicales, como erosión, perdida de nutrientes del suelo, competencia por el recurso hídrico, pérdida de biodiversidad y deterioro del paisaje (Beggs \& Moore, 2013).

En el caso específico de la palma aceitera, este monocultivo ha aumentado, principalmente en Malasia e Indonesia y se ha expandido rápidamente a regiones de África, Centroamérica y el Amazonas (Hernández et al., 2017). Se calcula que las plantaciones de palma aceitera actuales ocupan 17 millones de hectáreas y un potencial para su cultivo de $200 \mathrm{mi}$ llones de hectáreas (Pirker et al., 2016).

La palma fue introducida en Costa Rica en 1944 y la primera planta extractora de aceite fue construida en Damas (Aguirre) en el año 1950 y fue traída de Inglaterra. Para 1951 ya Costa Rica contaba con 3926 ha. de palma. En 1996 el área total plantada fue de 27698 ha. y en octubre de 1997 el área total de palma era de casi 29000 ha. (MAG, 2008). Para el año 2017, se tenía un total de 92456 ha. de palma aceitera sembradas, convirtiéndose en el cultivo de más área cultivada (La Nación, 2018) y además de tener un potencial de cultivo de 670800 hectáreas (MINAET, 2011). 
Según datos del Instituto Nacional de Estadísticas y Censos, el área sembrada aumentó de 66419 hectáreas en 2014 a 92456 hectáreas en 2017 (INEC, 2018), siendo Corredores, Osa y Golfito los cantones con mayor crecimiento de las plantaciones. En el cantón de Osa, específicamente, la expansión del cultivo de palma aceitera fomentó la pérdida y transformación de la vegetación natural de los distritos estudiados, así como el cambio de otro tipo de cultivos y pastos presentes en el cantón.

Además, después de décadas de esta expansión gradual de las áreas cultivadas de palma aceitera en el cantón de Osa y transformación de la vegetación natural, según diversos autores se menciona el impacto negativo que puede tener esta expansión sobre el clima, los suelos, los recursos hidrológicos, el desarrollo socioeconómico y la biodiversidad (Vitousek et al. 1997, Lambin et al. 2003). Este monocultivo acelera la pérdida de la biodiversidad, principalmente, por el incremento de la destrucción, degradación y fragmentación de los hábitats relacionados con el cambio de uso y cobertura de la tierra (Velázquez et al., 2002, Lambin et al., 2003). La conversión de la vegetación natural en espacios antrópicos causa un deterioro de los ecosistemas (Challenger 1998) por alterar la composición e interacción de especies, los procesos ecológicos y los regímenes de perturbación en todos los niveles (Hansen et al. 2004). La consecuente reducción de hábitats naturales influencia directamente el tamaño de las poblaciones y de la diversidad genética y puede llevar a una pérdida irreversible de especies (Flather et al. 1998). Este cambio y la deforestación de bosque para el cultivo de palma, trae consigo paisajes más homogéneos, con una menor diversidad original de ecosistemas y de especies sustentada por procesos ecológicos. Los remanentes de ecosistemas naturales están siendo reducidos por debajo del umbral del área requerida para su permanencia (Brooks et al. 1999) que determina directamente la persistencia de la biodiversidad, sólo preservada actualmente por las áreas protegidas del cantón y la presión que ejerce está expansión agrícola sobre ellas.

Este escenario de expansión requeriría evaluar el impacto de este cultivo en el cambio de uso de la tierra, identificar los cultivos o coberturas reemplazados y la presión que se ejerce sobre las áreas protegidas presentes en el cantón. 


\section{Marco Conceptual}

Dentro del análisis de las modificaciones realizadas por los seres humanos por la expansión gradual de las áreas cultivadas sobre la superficie terrestre y sobre el tema de este artículo se plantea la siguiente pregunta, ¿Hay diferencia entre uso actual de la tierra o cobertura?

Es importante diferenciar estos dos conceptos, aunque en muchos estudios de uso de la tierra no se les da la debida importancia. La importancia radica en la selección adecuada de las escalas de magnitud en el levantamiento de información básica. Posteriormente, esta se procesará para obtener resultados que permitan definir políticas de uso de la tierra a nivel nacional, local o de finca (Lucke, 1986). Forero hace una revisión de literatura y concluye que "cuando la tierra es explotada o empleada por el ser humano, se puede decir que es uso de la tierra". La cobertura terrestre la define como un ambiente natural producto de un sistema ecológico, mientras que el uso de la tierra es un ambiente artificial creado por el ser humano (Forero, 1981).

Además, a menudo se puede ver en el quehacer técnico diario, así como en la literatura científica relacionada con el manejo de los recursos naturales, cierta tendencia a confundir uso de la tierra con uso del suelo.

La FAO desde 1976 define el concepto tierra como un concepto más amplio que el suelo, estableciendo que las tierras comprenden el ambiente físico, incluyendo el clima, relieve, suelos, hidrología y vegetación en la medida que estos influyen en el potencial de empleo de tierras. El concepto incluye las actividades humanas presentes y del pasado con sus resultados tanto favorables como adversos. Las características puramente económicas y sociales pertenecen al contexto económico y social y no se incluyen en el concepto (Lucke, 1986).

Además, en la literatura se encuentran diversos conceptos en torno al cambio uso de la tierra/cobertura, definiendo en unos casos como el tipo de transformación ocurrida en una unidad espacial (Turner et al., 1995), la consecuencia de las relaciones causales establecidas entre sucesivos estados del mundo real (Allen et al., 1995), la extensión superficial de un tipo de cubierta que cambia a otra categoría (Briassoulis,1999), o el proceso dinámico que refleja una secuencia de decisiones tomadas por los usuarios de la tierra (Walker, 2003). En otros casos, se asocia el cambio en el uso de la tierra a la expresión material de la dinámica humana, ambiental y sus interacciones 
(Briasoulis, 1999) o se enuncian las diferencias entre uso y cobertura, al definir los cambios en el uso como las transformaciones acumuladas de la cobertura (Lambin et al., 1997) y los cambios de la cobertura como un producto de la acción deliberada o inadvertida del uso (Taylor et al., 2000).

Las diferencias entre uso y cobertura son remarcadas por algunos autores, en tanto que el tipo de ocupación de la superficie terrestre es obtenida de la información captada por sensores remotos, específicamente, sobre la señal emitida por los objetos, la cual no siempre indica el uso al que se destinan los mismos (Chuvieco, 2002; Seto et al., 2002). Por lo tanto, los límites de la cobertura no necesariamente coinciden con los del uso (Jansen y Di Gregorio, 2002). Sobre estos argumentos también se apoyan Seto et al. (2002) para establecer diferencias entre cambios en la cobertura y cambios en el uso, siendo este último más difícil de cartografiar, por cuanto necesita de información adicional que no es registrada por los sensores remotos. Estas consideraciones permiten explicar el empleo del término uso/cobertura en los títulos de algunas publicaciones, por ejemplo, en los estudios sobre detección de cambios que se apoyan en mapas levantados de la interpretación de imágenes satelitales, donde se delimita tanto la vegetación natural como el uso agrícola implícito en las cubiertas de cultivos registrados en los espacios considerados; tal es el caso que nos ocupa.

Para la tipificación de los cambios en el uso/cobertura de la tierra, se parte en la literatura de dos perspectivas o dimensiones que se exponen seguidamente:

\section{La dimensión temporal}

En estudios dinámicos o de análisis de series temporales esta dimensión es examinada mediante la estimación de las tasas a que progresan los cambios ocurridos en más de dos momentos del tiempo (Roy \& Tomar, 2001).

En análisis estáticos o casi estáticos (Briassoulis, 1999), también calificados por Marceau et al. (2001) como modelo foto (snapshot), se evalúa la información de las entidades y atributos presentes en un espacio, pero sólo en dos fechas específicas. Desde esta óptica los patrones de cambios identificados dependen de la extensión del intervalo de tiempo analizado, pero no reflejan la dinámica que puede ocurrir dentro del mismo. Sin embargo, limitaciones de recursos y de las fuentes de datos, disponibilidad 
tecnológica y otros factores conducen a muchos investigadores a utilizar este modelo (Aldana y Bosque, 2008).

\section{La dimensión espacial}

Con el auge de los Sistemas de Información Geográfica y su inclusión en diversos campos científicos como las ciencias sociales y naturales (Geografía, Ciencias Forestales, Ciencias Ambientales, Ecología), el estudio de la dimensión espacial se concreta, en la mayoría de los trabajos, a la localización, distribución y organización de las unidades transformadas y a la identificación de las estructuras o patrones espaciales (Aldana y Bosque, 2008). En menor medida se aborda en algunos trabajos específicos, los factores causales de los cambios y los procesos subyacentes. Aunque Briassoulis (1999) agrega al tema otros aspectos como: los flujos de interacción y los cambios en la disponibilidad de factores de producción. El patrón espacial refleja entonces la localización, distribución, organización (Pan et al., 2004), estructura (Lausch y Herzog, 2002) y dirección del cambio (Ochoa y González, 2000) de las unidades consideradas. A nivel regional y local, se han desplegado otros términos como: conversión para describir el cambio de un tipo de cubierta por otra y modificación cuando no se operan cambios de categoría, pero si se detecta algún nivel de afectación en uno o varios atributos de esta (Lambin et al., 2003).

Por otra parte, para el cómputo de los cambios en el uso/cobertura de la tierra se distinguen en la literatura tres tendencias generales: los trabajos en que sólo se estima el cambio neto mediante la diferencia entre las superficies ocupadas por cada categoría en las fechas consideradas (Perz y Skole, 2003); aquellos en que se emplean funciones específicas desplegadas en SIG raster como ArcGis e Idrisi, para interceptar dos mapas de uso/cobertura de la tierra de dos fechas distintas, generándose un mapa de cruce y una matriz de transición, la cual aporta los datos para el cálculo del cambio neto, las ganancias y las pérdidas ocurridas en cada cubierta terrestre (Xiuwan, 2002); y, en tercer lugar, los trabajos que se apoyan en el procedimiento anterior pero, además de las categorías enunciadas incluyen una recientemente diferenciada por Pontius et al. (2004), es decir, el intercambio o la superficie perdida por una cubierta en un lugar determinado, que simultáneamente, se incrementa en otro. Este nuevo componente es incorporado por el autor en el cómputo del cambio total, el cual se divide 
por 2 para evitar la duplicidad de superficies en las operaciones realizadas, por cuanto el cambio en un píxel representa simultáneamente la pérdida de una categoría y la ganancia de otra.

\section{Metodología}

El análisis del cultivo de palma aceitera en el cantón de Osa se realizó en dos etapas: 1) compilación de información sobre área sembrada en el cantón y distritos de Osa, y 2) análisis del cambio de área sembrada de los años 2014 al 2018.

Para la etapa $\mathrm{n}^{\circ} 1$, los datos del área sembrada de palma aceitera se obtuvieron de los Censos Nacionales Agropecuarios (INEC, 2014), del año 2014. Además, la Encuesta Nacional Agropecuaria (INEC, 2017), del año 2017. Estos datos eran importantes para conocer el área sembrada en 2014 y 2017 y comparar esos resultados con el proceso de digitalización y trabajo de campo desarrollado para el mapeo del área sembrada de la palma aceitera de esos años. Cabe destacar que el INEC sólo presentó datos generales del área sembrada de palma aceitera y por confidencialidad no se obtuvieron mapas de distribución de la palma. El estudio se realizó en el cantón de Osa, Puntarenas (Mapa 1), adscrito al proyecto código 0537-15 "Tendencias, riesgos e impactos asociados al cultivo de la palma aceitera en el Pacífico Sur, como insumo para la previsión de prácticas y políticas que promuevan una producción sustentable y segura en Costa Rica PIPALSur", del Instituto Regional de Estudios en Sustancias Tóxicas (IRET), de la Universidad Nacional. 
Mapa 1. Ubicación cantón de estudio.

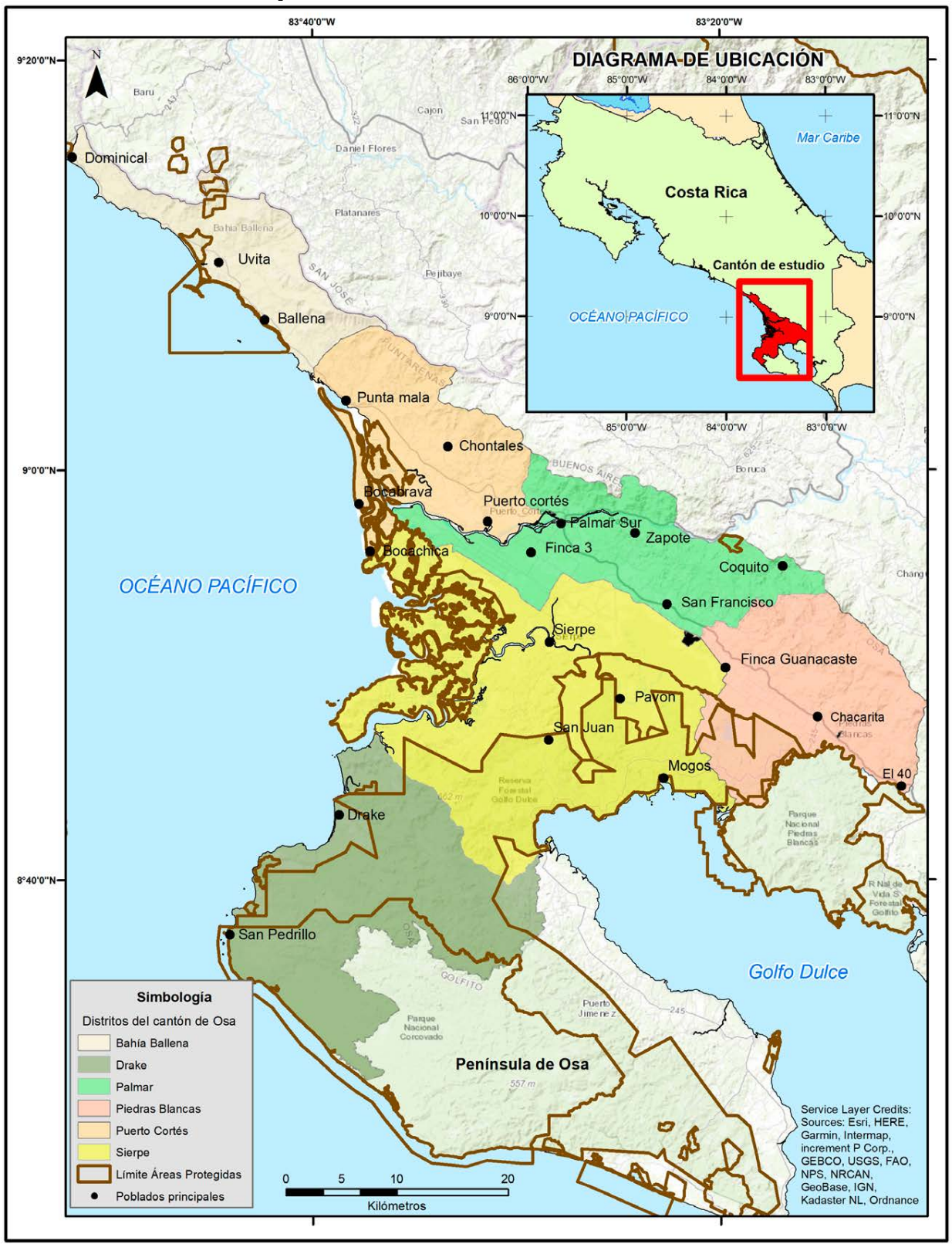

100 Revista Geográfica de América Central. No 65(2)

ISSN 1011-484X • e-ISSN 2215-2563 / Julio-diciembre 2020 
En la etapa $\mathrm{n}^{\mathrm{o}} 2$, el análisis del cambio en áreas de cultivo de palma aceitera se realizó identificando y digitalizando la ubicación de las áreas cultivadas con palma aceitera en los años 2014 y 2018. Para el proceso de digitalización, se usaron las imágenes de Google Earth ${ }^{\circledR}$ disponibles para el cantón de Osa y las imágenes "basemap" del programa ArcGis que se pudieron obtener al contar la Universidad Nacional con las licencias respectivas. En total se digitalizaron 737 polígonos de palma aceitera, de los cuales el $37 \%$ correspondieron al 2014 y el $63 \%$ al 2018 , donde el tamaño promedio fue de 16 hectáreas, con una variación de tamaños entre 0,1 hectáreas y las 779 hectáreas. Las áreas donde se digitalizaron los polígonos de palma aceitera fueron en las plantaciones maduras, ya que las características de textura, color y forma son muy características y permiten distinguirlas de otros usos/coberturas. Figura 1.

Además, se realizó una conversión de los archivos de palma aceitera en formato vectorial al formato ráster, para identificar el cambio de uso/coberturas hacia el cultivo de palma, específicamente, la transición que había entre el año 2012 y el año 2018. Para ello, se realizó una matriz transicional de la palma de 2018 con otros usos/coberturas que se obtuvieron a partir de imágenes satelitales RapidEye 2012, realizado por el Ministerio de Ambiente y Energía. Los usos y coberturas que se seleccionaron fueron: bosque, bosque secundario, cultivos, pasto y manglar. Cabe mencionar, que el archivo de uso y coberturas 2012 se obtuvo en formato vectorial del Sistema Nacional de Información Territorial (SNIT) y las imágenes satelitales 2014 y 2018 se encontraban con su respectiva corrección radiométrica y geométrica. Esto porque la casa

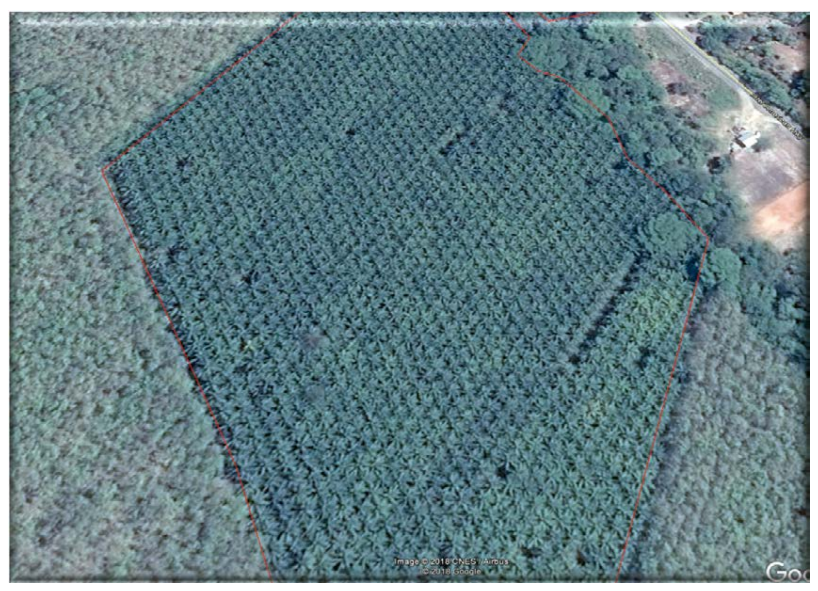

Figura 1. Ejemplo delimitación palma aceitera con imagen de Google Earth ${ }^{\circledR}$. 
ESRI, creadora del programa ArcGis presenta las imágenes en el software para su uso respectivo.

Como se mencionó anteriormente, se realizó una matriz transicional para mostrar la dinámica espacio temporal del cambio usos/coberturas y el cultivo de palma aceitera. Para ello, la cartografía vectorial del cultivo de palma aceitera de 2018 fue transformada a formato ráster con una resolución de celda de $10 \mathrm{~m}$, la cual fue utilizada para calcular la matriz de transición para el período 2012-2018. Este análisis consiste en la sobreposición cartográfica y una tabulación cruzada empleando dos fechas (fecha 1 y fecha 2), para definir un intervalo de tiempo. Como resultado se obtuvo una matriz, que es una tabla de arreglos simétricos que contiene en el eje horizontal las categorías de uso y cobertura de la tierra para la primera fecha, mientras que en el eje vertical tiene la información proveniente de la siguiente fecha (Cuadro 1). La diagonal de la matriz representa la superficie de cada categoría de uso y cobertura de la tierra que permaneció sin cambios durante el periodo considerado, mientras que en el resto de las celdas muestra la superficie que experimentó un cambio hacia algún otro tipo de categoría. En nuestro caso nos interesa la primera columna porque allí se presentan las categorías de uso/cobertura que cambiaron a palma aceitera entre el 2012 y 2018 . A partir de la matriz de cambio se estimó la ganancia, la pérdida y la estimación del intercambio entre palma aceitera y los usos/coberturas. Para el presente estudio, las celdas 21,31,41,51 y 61 son las que cambiaron de uso/cobertura de 2012 a palma aceitera en 2018 y los números 11, 22, 33, 44, 55 y 66 mantuvieron el mismo uso/cobertura (Farfán et al., 2008). 
Denis Mauricio Salas-González

Changes in the area cultivated with oil palm in the canton of Osa, Puntarenas. 2014-2018 period

Cuadro 1. Matriz transicional usos/coberturas 2012-2018.

\begin{tabular}{|c|c|c|c|c|c|c|c|c|}
\hline \multirow{2}{*}{\multicolumn{3}{|c|}{$\begin{array}{l}\text { Matriz de cambio de uso/ } \\
\text { cobertura de la tierra }\end{array}$}} & \multicolumn{6}{|c|}{ Año 2018} \\
\hline & & & \multirow{2}{*}{$\begin{array}{c}\text { Palma } \\
1\end{array}$} & \multirow{2}{*}{$\begin{array}{c}\text { Bosque } \\
2 \\
\end{array}$} & \multirow{2}{*}{\begin{tabular}{|c|}
$\begin{array}{c}\text { Bosque } \\
\text { secundario }\end{array}$ \\
3 \\
\end{tabular}} & \multirow{2}{*}{$\begin{array}{c}\text { Cultivos } \\
4 \\
\end{array}$} & \multirow{2}{*}{$\begin{array}{c}\text { Pasto } \\
5 \\
\end{array}$} & \multirow{2}{*}{$\begin{array}{c}\text { Manglar } \\
6\end{array}$} \\
\hline & & & & & & & & \\
\hline Año & Palma & 10 & 11 & 12 & 13 & 14 & 15 & 16 \\
\hline \multirow[t]{5}{*}{2012} & Bosque & 20 & 21 & 22 & 23 & 24 & 25 & 26 \\
\hline & $\begin{array}{c}\text { Bosque } \\
\text { secundario }\end{array}$ & 30 & 31 & 32 & 33 & 34 & 35 & 36 \\
\hline & Cultivos & 40 & 41 & 42 & 43 & 44 & 45 & 46 \\
\hline & Pasto & 50 & 51 & 52 & 53 & 54 & 55 & 56 \\
\hline & Manglar & 60 & 61 & 62 & 63 & 64 & 65 & 66 \\
\hline
\end{tabular}

Fuente: elaboración propia

\section{Resultados}

La zona de estudio comprende el cantón de Osa de la provincia de Puntarenas, Costa Rica. El objetivo general de la investigación fue analizar el cambio en el área sembrada con el cultivo de palma aceitera durante el periodo 2014-2018 y estimar el crecimiento y distribución espacial del cultivo.

El área de cultivo de palma aceitera en Costa Rica aumentó, aproximadamente, cinco veces en los últimos treinta años. En 1989 se tenían poco más de 20000 hectáreas (SEPSA, 2018) y 92456 en el año 2017 (INEC, 2018). Gráfico 1.

Gráfico 1. Cultivo de palma aceitera en Costa Rica, período 1989-2017.

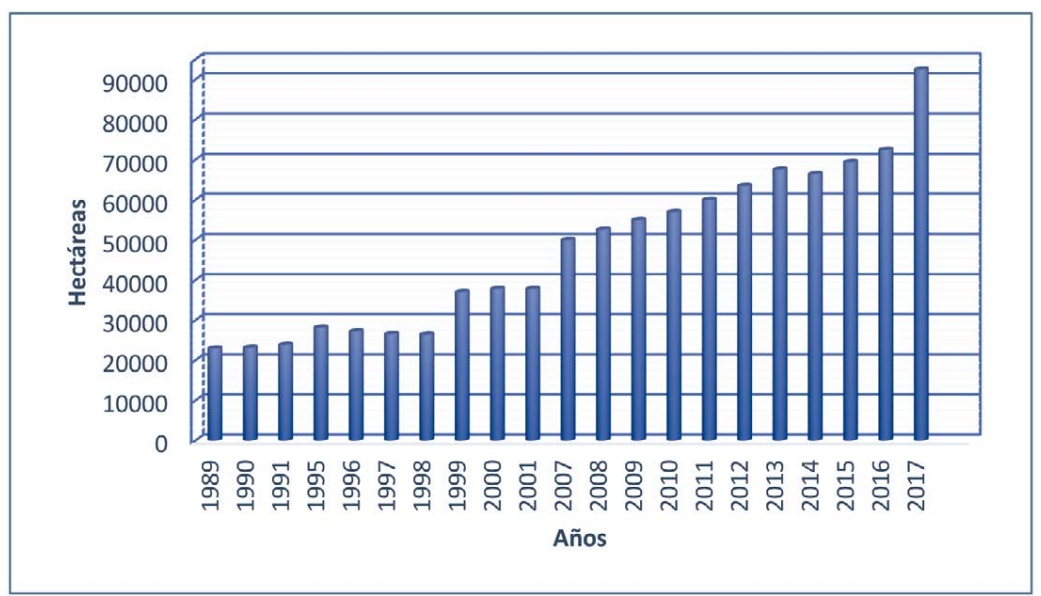

Fuente: elaboración propia 
La tendencia nacional en la expansión de la plantación se refleja en los cantones de Osa y Golfito, donde los pequeños propietarios y grandes propietarios reciben a la fecha los beneficios de cosechas predecibles todo el año e igualmente una demanda consistente. Debido a la historia de fracasos y vulnerabilidad de mercados experimentada con productos agrícolas previos en la región (cacao, banano, arroz, ganadería), la palma aceitera es vista como motor de la actividad económica, que puede o no ser sostenible en el largo plazo a nivel social, económico y ambiental. Sin embargo, este sector continúa en crecimiento (Beggs \& Moore, 2013).

De acuerdo con Mingorance et. al., (2014), las condiciones óptimas para el cultivo de palma aceitera son de una altitud máxima de $500 \mathrm{msnm}$ con pendientes menores a $23 \%$, los suelos deben ser planos o poco ondulados, suelos francos y con buen drenaje, el pH debe ser neutro o moderadamente ácido, máximo con $\mathrm{pH}$ de 4 . La temperatura debe oscilar entre $\operatorname{los} 23^{\circ}$ y $33^{\circ} \mathrm{C}$, siendo está la más alta, precipitaciones entre $1800 \mathrm{~mm}$ y $2200 \mathrm{~mm}$ anuales y humedad relativa de $80 \%$.

Tales características han permitido que muchas zonas del territorio nacional se conviertan, en zonas sumamente aptas para este cultivo, y de allí el gran crecimiento de este durante los últimos 30 años. También en ese lapso se han dado fluctuaciones en la producción de palma debido a cambios a nivel mundial del precio del aceite, enfermedades como la flecha seca, políticas estatales de fideicomisos para el sector palmero y la incorporación a planes del sector energía de nuestro país de aceite de palma para biocombustibles.

El área sembrada en el año 2014 en el cantón de Osa fue de 6 593,56 hectáreas (CENAGRO, 2014). Estos cultivos se establecieron en terrenos que anteriormente contaban con otro tipo cultivos agrícolas y explotación comercial (cacao, banano, arroz, ganadería) que no perduraron por una historia de fracasos y vulnerabilidad de mercados (Begg \& Moore, 2013). Además, eran cultivos sembrados en pendientes menores a $5 \%$ para facilitar los procesos de producción. La distribución del área sembrada por distrito para el año 2014 se observa en el cuadro 2, donde los distritos de Sierpe, Piedras Blancas y Palmar contaban con la mayor cantidad de palma aceitera sembrada, mientras que, en Bahía Ballena, Puerto Cortés y Bahía Drake, los cultivos de palma apenas contaban con unas centenas de hectáreas, ya que eran distritos con una vocación turística y zona de paso entre las ciudades del Valle Central y la Zona Sur del país. 
Denis Mauricio Salas-González

Changes in the area cultivated with oil palm in the canton of Osa, Puntarenas. 2014-2018 period

Cuadro 2. Datos principales del cultivo de palma aceitera 2014-2018.

\begin{tabular}{|c|c|c|c|c|c|c|}
\hline Distrito & $\begin{array}{c}\text { Área en } \\
\text { ha. del } \\
\text { distrito }\end{array}$ & $\begin{array}{c}\text { Ha. de } \\
\text { palma en } \\
\mathbf{2 0 1 4}\end{array}$ & $\begin{array}{c}\text { Ha. de } \\
\text { palma en } \\
\mathbf{2 0 1 8}\end{array}$ & $\begin{array}{c}\text { \% área de } \\
\text { palma por } \\
\text { distrito en 2018 }\end{array}$ & $\begin{array}{c}\text { \% del total } \\
\text { de palma } \\
\text { en 2018 }\end{array}$ & $\begin{array}{c}\text { \% de } \\
\text { aumento } \\
\mathbf{2 0 1 4 / 2 0 1 8}\end{array}$ \\
\hline Bahía Ballena & 16018,4 & 0 & 3 & 0,02 & 0,03 & - \\
Bahía Drake & 39025,1 & 256,2 & 368,3 & 0,94 & 3,17 & 35,41 \\
Puerto Cortés & 21796,3 & 183 & 1344 & 6,17 & 11,56 & 632,16 \\
Sierpe & 59623,9 & 2908,82 & 4181 & 7,01 & 35,96 & 39,98 \\
Palmar & 24444,2 & 1294,95 & 2930 & 11,99 & 25,20 & 124,11 \\
Piedras Blancas & 26429,1 & 1950,59 & 2800 & 10,59 & 24,08 & 41,83 \\
Total & $\mathbf{1 8 7 3 3 7}$ & $\mathbf{6 5 9 3 , 5 6}$ & $\mathbf{1 1 6 2 6 , 3}$ & & $\mathbf{1 0 0 , 0 0}$ & 76,33 \\
\hline
\end{tabular}

Fuente: elaboración propia

En el año 2018, la palma aceitera se convirtió en el cultivo principal del cantón de Osa, con un total sembrado de 11626 hectáreas, aproximadamente que fueron determinadas durante el presente estudio. A nivel distrital, Bahía Ballena se ubica con la menor cantidad de palma sembrada, pues solo cuenta con tres hectáreas en el año 2018, pues su principal actividad económica es el turismo. Cabe destacar que, en el año 2014, el Censo Nacional Agropecuario no reportó cultivo de palma aceitera en este distrito. En cuanto al crecimiento de palma aceitera sembrada en los otros distritos para el mismo periodo, se puede observar crecimientos acelerados de más de un $600 \%$ en el distrito de Puerto Cortés, pasando de 183 a 1344 hectáreas; sumándose a los distritos con más de 1000 hectáreas de palma sembrada. En tanto Sierpe, Palmar y Piedras Blancas continúan con crecimientos de más del 40\%, dentro de los que sobresalen los distritos de Palmar y Piedras Blancas donde más del $10 \%$ de su territorio está cubierto de palma aceitera. En los mapas siguientes las áreas sembradas de palma aceitera del año 2014 se mantuvieron también en el año 2018 (Mapas 2,3,4,5 y 6).

Este crecimiento ha sido favorecido por los ingresos económicos constantes que reciben los productores, el respaldo gubernamental como el fideicomiso 955-001 MH/BNCR y el Decreto Ejecutivo No 35091-MAG-MINAET, el Reglamento de Biocombustibles publicado en La Gaceta $N^{\circ} 53$ del 17 de marzo de 2009, que tiene por objetivo propiciar el desarrollo de una industria nacional de biocombustibles (MAG, 2012). Esto podría ser posible modificando el artículo 6 de la Ley de Monopolio de la Refinadora Costarricense de Petróleo (RECOPE) que permitiría su incursión en el tema de biocombustibles. 


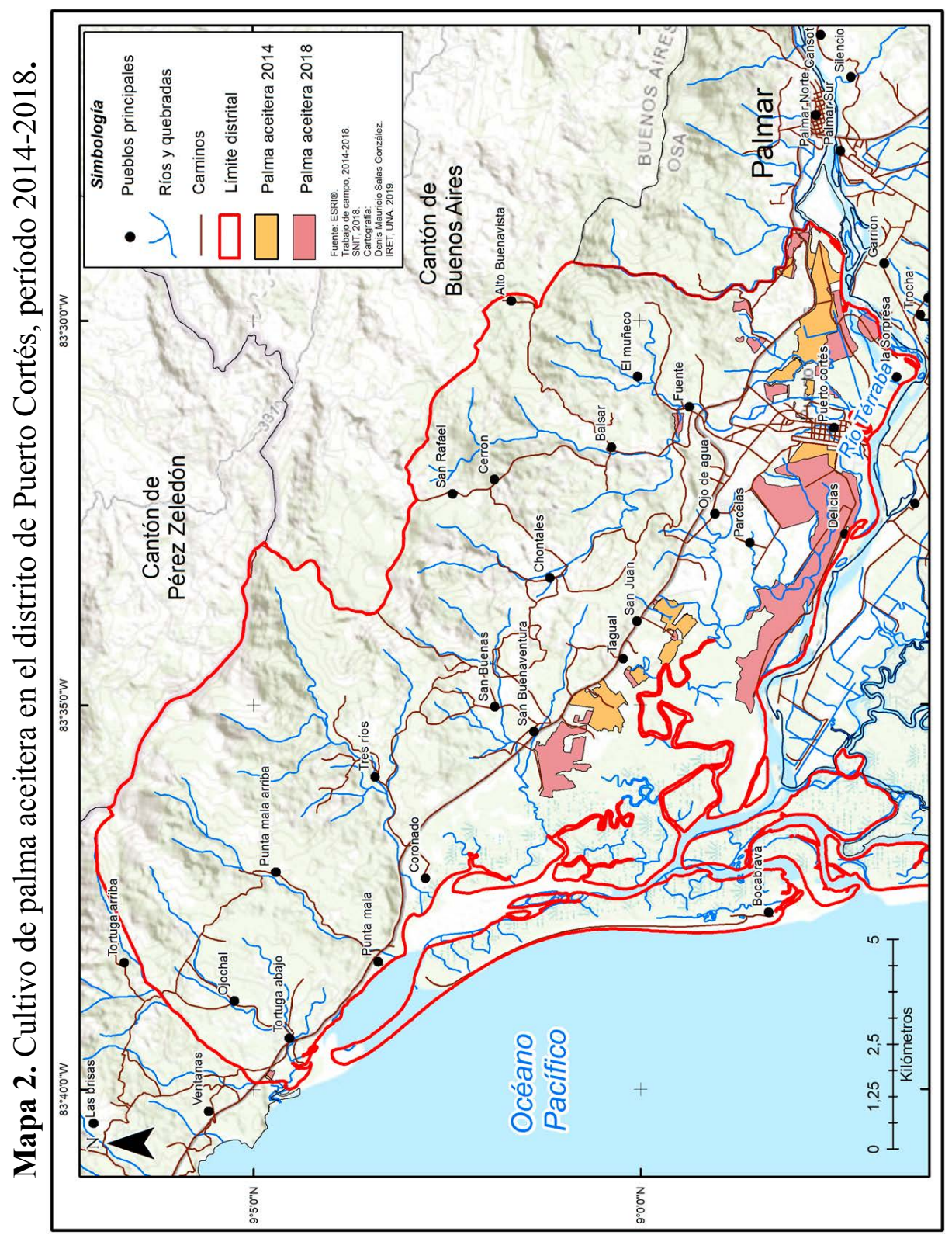


Denis Mauricio Salas-González

Changes in the area cultivated with oil palm in the canton of Osa, Puntarenas. 2014-2018 period

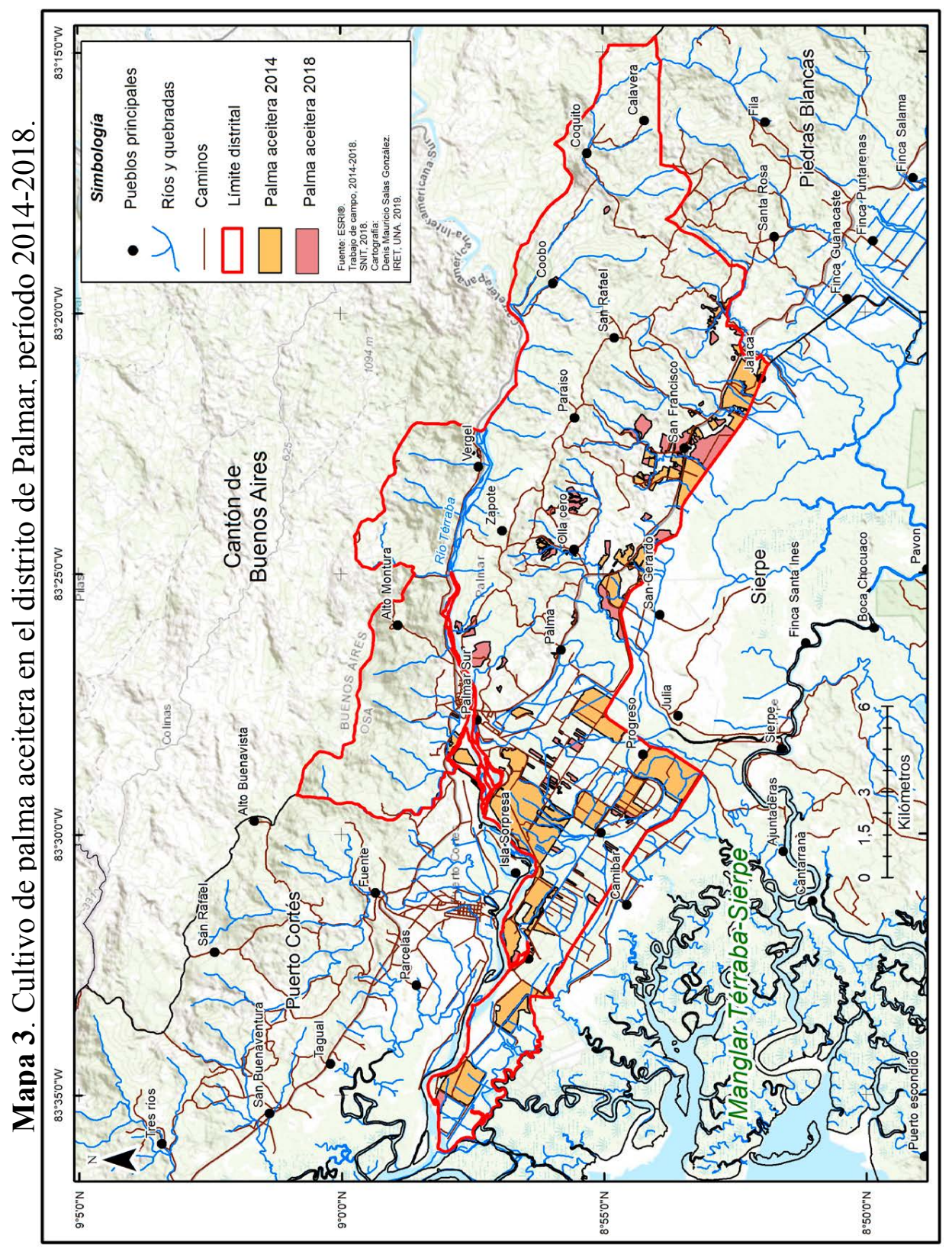




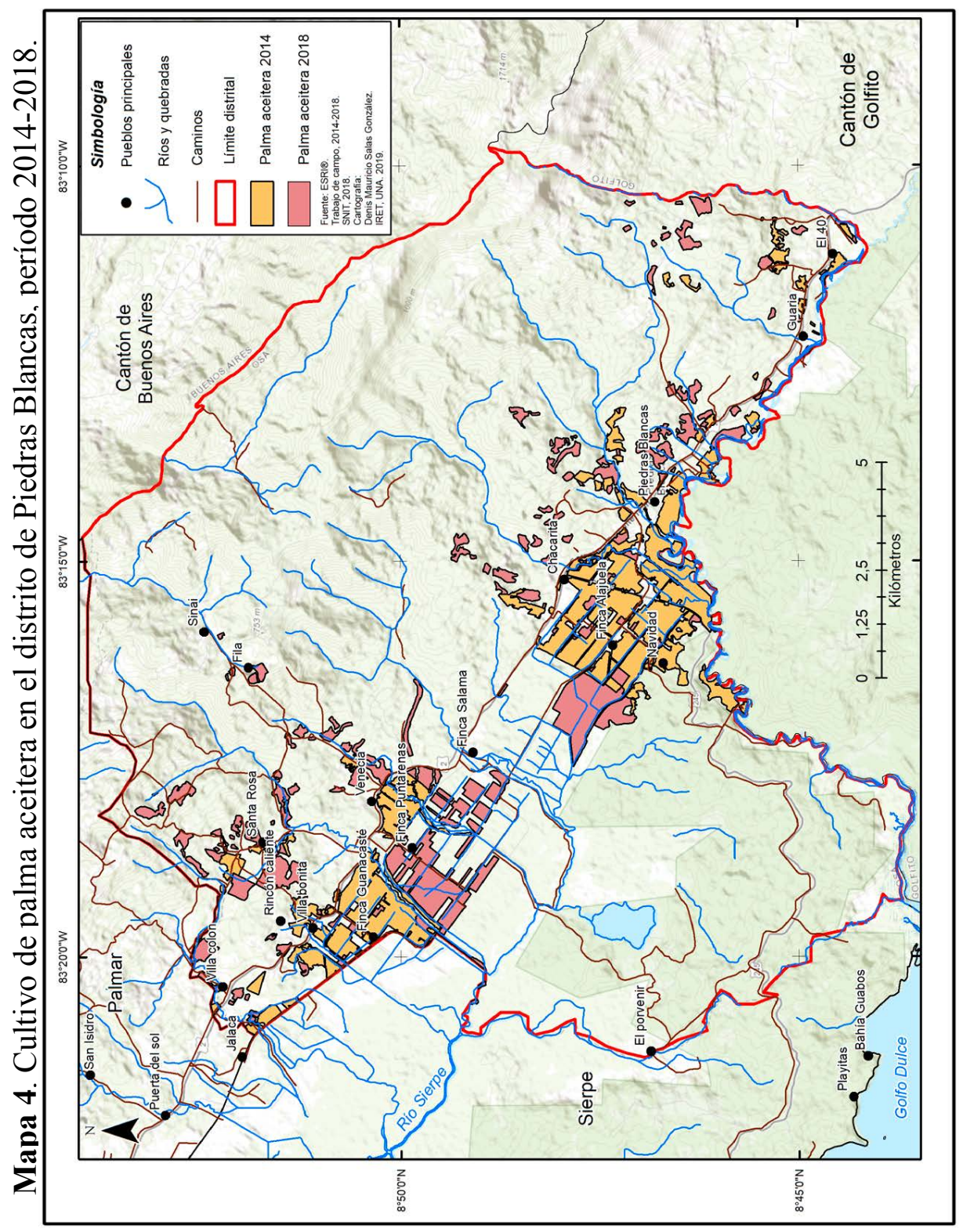


Denis Mauricio Salas-González

Changes in the area cultivated with oil palm in the canton of Osa, Puntarenas. 2014-2018 period

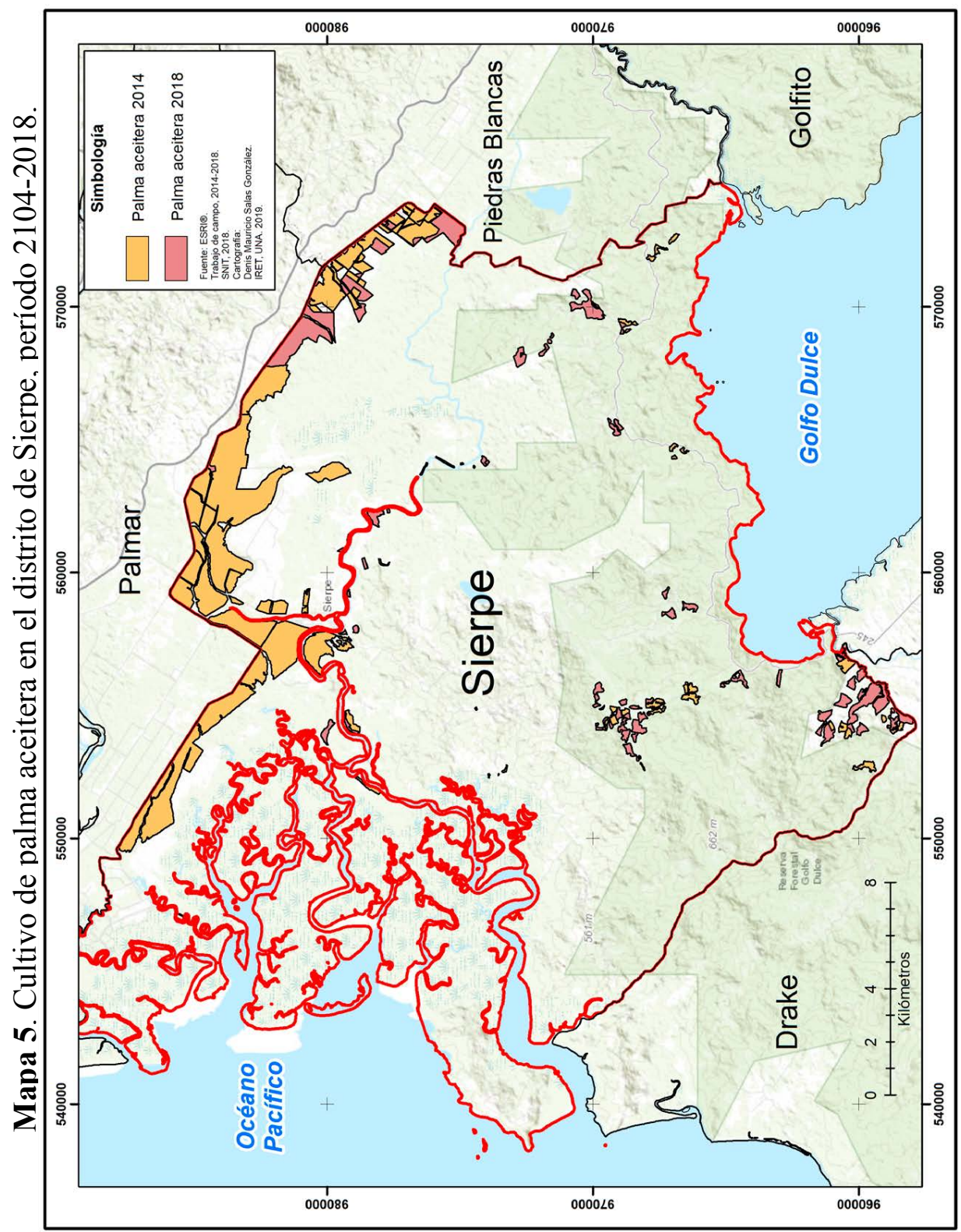


Mapa 6. Cultivo de palma aceitera en el distrito de Drake, período 2014-2018.

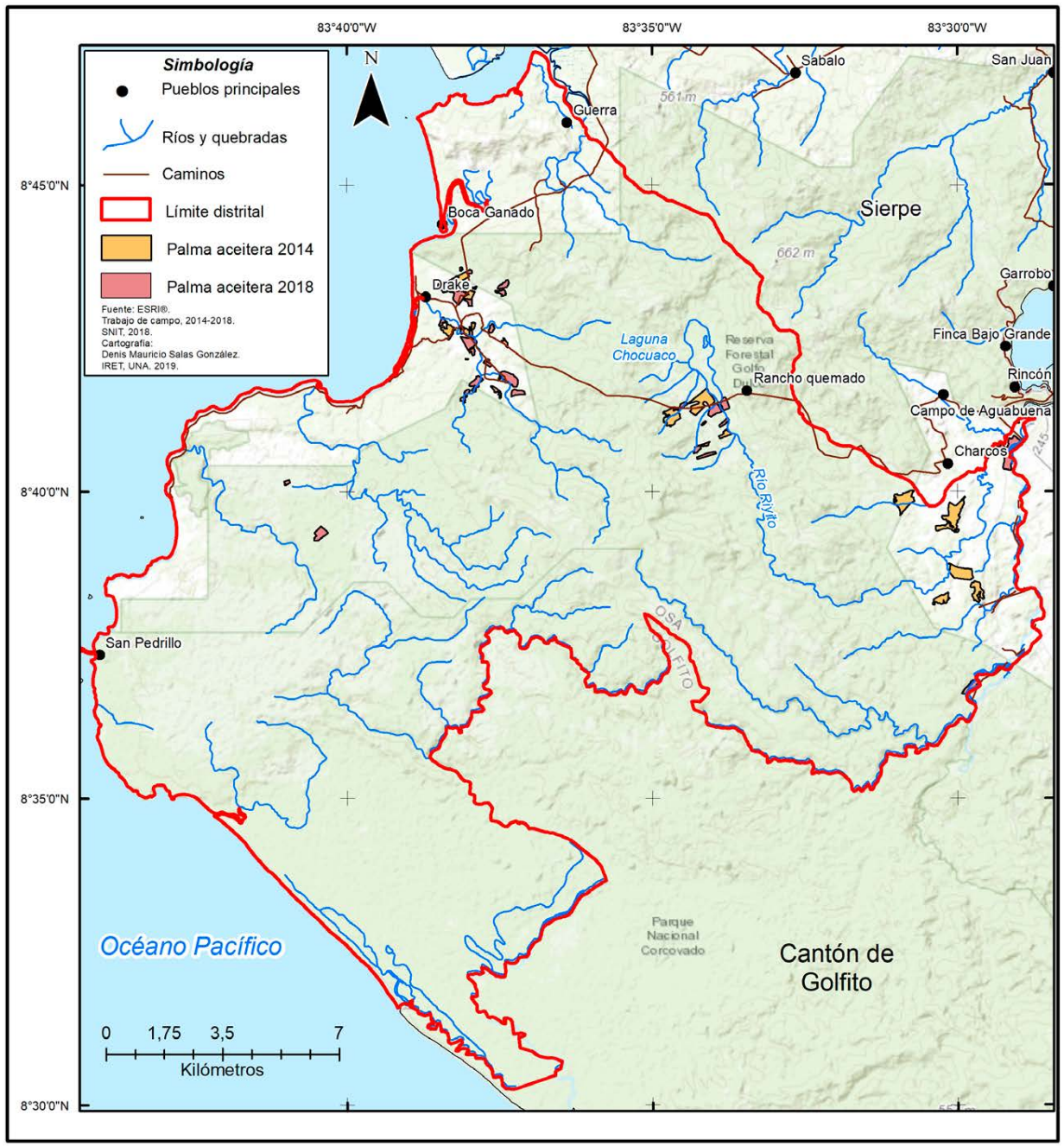

Otro cambio en la dinámica de siembra en el cantón de Osa fue, que las plantaciones de palma aceitera establecidas al año 2014, en su mayoría se realizaban en terrenos con pendientes de 0 a 3\%. Estas plantaciones estaban ubicadas en los valles de los ríos, que era lo característico para este cultivo y que se refleja en las 9417 hectáreas de palma que se mantienen en ese rango de pendientes en el año 2018. 
A partir de ese mismo año las plantaciones se comenzaron a ubicar en pendientes ligeramente onduladas hasta fuertemente onduladas de más del $60 \%$, constituyendo unas 2227 hectáreas, esto fomentado por la gran cantidad de caminos, caminos no sólo asfaltados, sino artesanales hechos con maquinaria precaria (caminos de tierra), que facilitan la extracción de bosque, plantaciones forestales y las nuevas plantaciones de palma. Mapa 7.

Sólo en el cantón de Osa el promedio era de dos kilómetros de caminos por cada kilómetro cuadrado en el 2014, pasando a cuatro kilómetros por kilómetro cuadrado, esto influenciado por el asfaltado de la ruta hacia Puerto Jiménez, pasando de pocos caminos en pobres condiciones a convertirse según Beggs \& Moore, (2013), "una frontera emergente para la expansión de palma aceitera dentro de la región Brunca”.

Mapa 7. Red de caminos en el cantón de Osa, período 2014-2017.

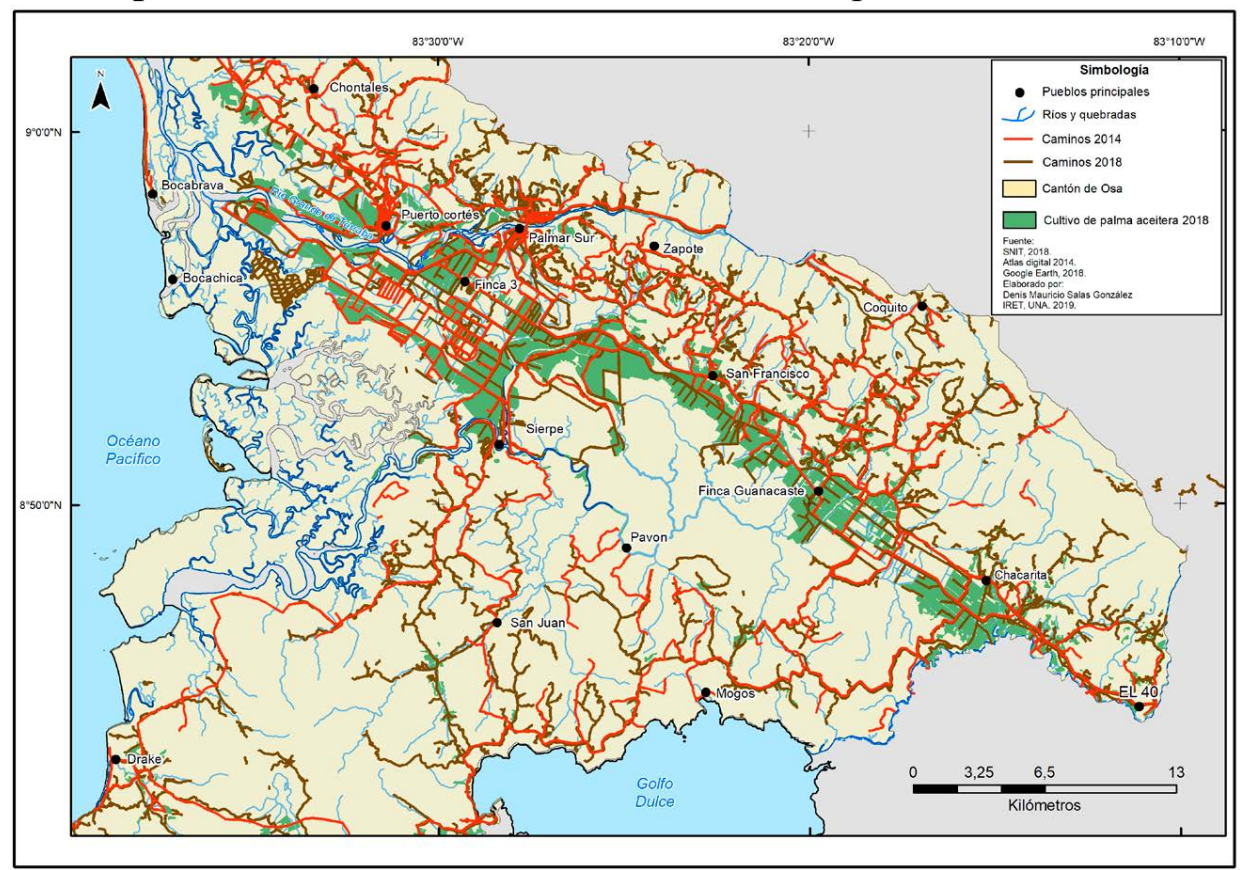

Además, aunque no es característico que las plantaciones de palma se ubiquen en estas fuertes pendientes, es claro que la búsqueda de alternativas para el cantón ha dado lugar a que más de tres mil hectáreas lo estén, lo que trae consigo mayores costos en la siembra, en la cosecha y mayores 
costos de mantenimiento general, aportando menos beneficios a los productores y posibles efectos aún no determinados de uso de agroquímicos y pérdida de cobertura boscosa. La figura 2 muestra el cambio de pendiente $\mathrm{y}$ altitud en las plantaciones de palma aceitera en el cantón de Osa.

Figura 2. Cambio en pendientes y altitud de las plantaciones de palma, Sector El 40. Cantón de Osa.

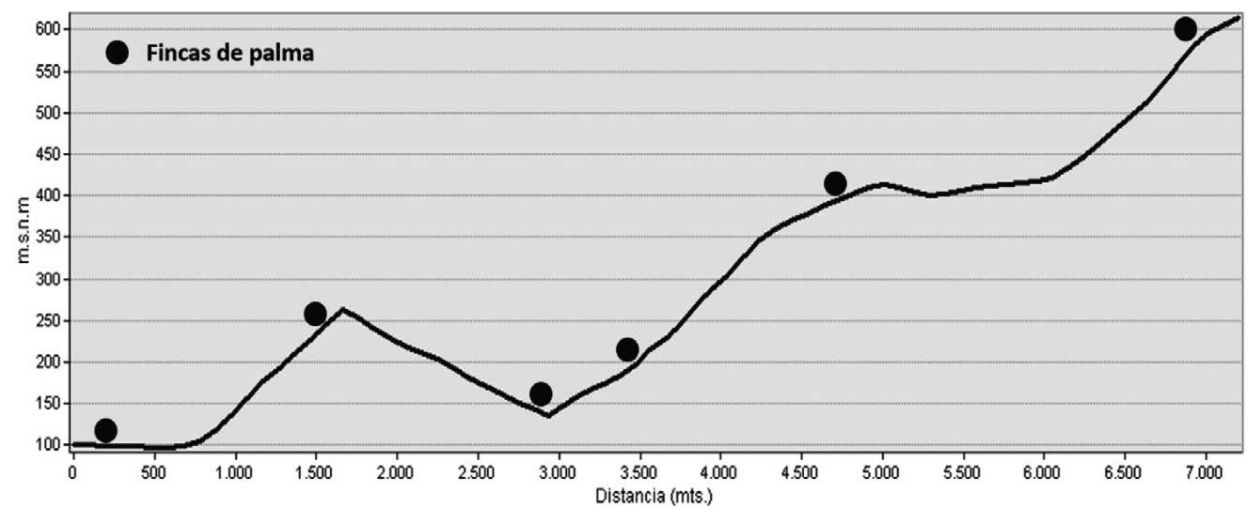

Este estudio también determinó un aproximado de las coberturas vegetales que fueron reemplazadas por la palma aceitera en el periodo 20122018. Utilizando el mapa de uso de la tierra a partir de imágenes satelitales RapidEye 2012, realizado por el Ministerio de Ambiente y Energía, permitió usar los usos y coberturas vegetales de ese año, para determinar las áreas que ocupaban las plantaciones de palma en el año 2018, donde tres tipos de coberturas, principalmente, fueron las que cedieron su lugar a la palma aceitera.

En primer lugar, las áreas de pastizales con aproximadamente 1544 hectáreas, un 30,68\% de las nuevas plantaciones de palma, el bosque secundario con 949 hectáreas, un 18,35\% y plantaciones forestales con una superficie aproximada de 471 hectáreas, representando un $9,36 \%$ de las nuevas plantaciones entre 2014 y 2018 . La figura 12 muestra como ese cambio se da principalmente en las plantaciones de pendientes onduladas y muy onduladas del cantón. 
Mapa 8. Cambios de coberturas a cultivos de palma aceitera, período

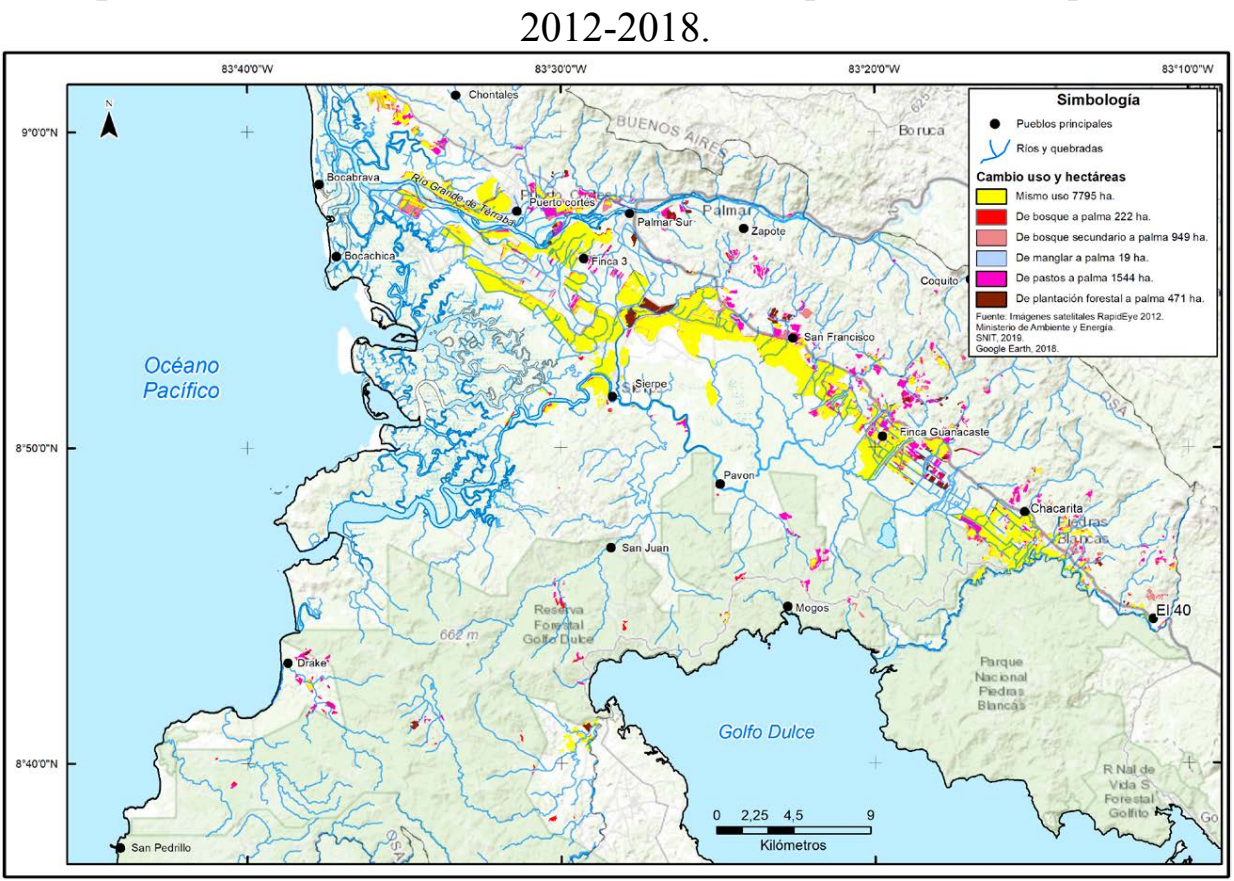

Este crecimiento de la palma aceitera en pendiente y el cultivo histórico en zonas planas, tiene una importante incidencia en la presión sobre las áreas protegidas, no solo del cantón, sino de toda la Zona Sur del país, ya que las áreas de amortiguamiento que antes se tenían con respecto a estas áreas, cambiaron para dar paso a este monocultivo, trayendo consigo las consecuencias de la deforestación, la creación, como se mencionó anteriormente, de nuevos caminos y generando sobre los productores falta de tierras para la expansión de otros cultivos, así como aumento en el precio de éstas.

Esta expansión contempla una nueva ampliación de la frontera agrícola y como menciona Dirzo et al (2012), permanecen vacíos significativos lo que no permite comprender el impacto socioeconómico y ambiental de la expansión de la palma aceitera. Ya suceda o no, que las plantaciones estén comprometiendo los ecosistemas locales y la biodiversidad, lo cual sigue siendo desconocido. 


\section{Conclusiones}

Los polígonos identificados para este estudio son una muestra significativa del cultivo de palma aceitera en el cantón de Osa y un esfuerzo por conocer la configuración, ubicación y tamaño de sus plantaciones, así como donde se están ubicando las nuevas plantaciones respecto a la pendiente y la altitud, algo que cambia el patrón de siembra que se ha dado desde el inicio del proceso de cultivo de palma aceitera en Costa Rica.

El remplazo de bosque secundario, plantaciones forestales y pastos por cultivos de palma aceitera muestra la competencia por el uso y cobertura de la tierra y el problema que se puede tener por la presión que se ejerce sobre las áreas protegidas y la expansión de la frontera agrícola.

Los ingresos económicos que los productores obtienen por la siembra de palma aceitera son el gran atractivo para que las tendencias de expansión de la palma se mantengan y continúen. Esto genera problemas, porque, aunque el uso de agroquímicos, herbicidas y fertilizantes son bajos para el cultivo, por el proceso de cambio de pendientes puede ser un problema, pues facilitan los procesos de erosión y el lavado por de éstos, y por lo tanto su posible incursión dentro de los procesos hidrológicos de las cuencas de la zona.

Se debe realizar cooperación con la municipalidad de Osa, para tomar en cuenta estos informes en planes reguladores y planes de ordenamiento regional, para la regulación de este cultivo y si se pudieran realizar procesos de certificación de plantaciones sustentables de palma aceitera, ya que iniciativas a nivel mundial comienzan a darse con respecto a ésta, como por ejemplo Noruega, donde como parte del compromiso de este país para eliminar la deforestación en el mundo, el parlamento votó a favor de prohibir la compra de biocombustibles con productos de palma que no demuestren que fueron producidos de manera sostenible y evitará su compra a partir del primero de enero del año 2020, ya que según Greenpeace, la industria de la palma de aceite -junto a la ganadería vacuna y la soya- se han convertido en los peores motores de la deforestación en todo el planeta (El Espectador, 2019). 
Denis Mauricio Salas-González

Changes in the area cultivated with oil palm in the canton of Osa, Puntarenas. 2014-2018 period

\section{Referencias}

Aldana Dezzeo, A. \& Bosque Sendra, J. (2008). Cambios ocurridos en la cobertura/uso de la tierra del Parque Nacional Sierra de la Culata. Mérida-Venezuela. Período 1988-2003, GeoFocus (Artículos), ${ }^{\circ}$ (8), p. 139-168, ISSN: 1578-5157.

Allen, E., Edwards, G., y Bédard, Y. (1995). Qualitative causal modeling in temporal GIS", en Frank y Kuhn (Eds.), Spatial information theorya theoretical basis for GIS (COSIT'95), (397-412). Lecture Notes in Computer Science. Austria, Springer-Verlag.

Beggs, E. \& Moore, E. (2013). El Paisaje Social de la Producción de Aceite de Palma Africana en la Región de Osa y Golfito, Costa Rica. San José, Costa Rica. INOGO, Stanford Woods Institute for the Environment.

Briassoulis, H. (1999). Analysis of land use change: Theoretical and modeling approaches. The web Book of Regional Science, Regional Research Institute, West Virginia University. Recuperado de http:// www.rri.wvu.edu/WebBook/Briassoulis/.

Brooks, T. \& Tobias J. et al. (1999). Deforestation and bird extinctions in the Atlantic forest, Animal Conservation 2, 211-222.

Clare Rhoades, P. (2011). Los cambios en la cadena de producción de la palma aceitera en el Pacífico costarricense: Una historia económica, socioambiental y tecnocientífica, 1950-2007. 1a edición San José, Costa Rica, Sociedad Editora Alquimia 2000258 p.; ilus., maps.; 25 x $18 \mathrm{~cm}$.

Challenger, A. (1998). Utilización y conservación de los ecosistemas terrestres de México, pasado presente y futuro. Comisión Nacional para el Conocimiento y Uso de la Biodiversidad, Instituto de Biología, UNAM, Agrupación Sierra Madre S.C., México.

Chuvieco Salinero, E. (2002). Teledetección ambiental. La observación de la Tierra desde el espacio. Barcelona, España, Ariel Ciencia.

Díaz Beltrán, A. (2017). Análisis multitemporal del crecimiento del área sembrada en palma africana (Elaris guincensis) y su efecto en los espacios naturales en la zona de los Llanos Orientales de Colombia. Facultad de Ingeniería. Universidad Militar Nueva Granada.

Dirección Provincial de Ordenamiento Urbano y Territorial (DPOUT). (2011). Sistemas de Información Geográfica para el ordenamiento 
territorial. Recuperado de http://www.mosp.gba.gov.ar/sitios/ urbanoter/sig/Manual_SIG_UT.pdf.

Farfán G., Michelle, G. Rodríguez-Tapia \& Mas, J. F. (2016). Análisis jerárquico de la intensidad de cambio de cobertura/uso de suelo y deforestación (2000-2008) en la Reserva de la Biosfera Sierra de Manantlán, México, Investigaciones Geográficas, (90), 89-104. Instituto de Geografía, UNAM, México, http://dx.doi.org/10.14350/ rig. 48600 .

Flather, C.H., Knowles, M.S. \& Kendall, I.A. (1998). Threatened and endangered species geography. BioScience (48): 365-376.

Forero, M.C. (1981). Levantamiento de cobertura terrestre y uso de la tierra. Centro Interamericano de Fotointerpretación, Unidad de Suelos y Agricultura. Bogotá, Colombia.

Hansen A.J., DeFries R., Turner W. (2004). Land Use Change and Biodiversity: A Synthesis of Rates and Consequences during the Period of Satellite Imagery. In: Gutman G. and Justice C. (eds.) 2004. Land Change Science: Observing, Monitoring, and Understanding Trajectories of Change on the Earth's Surface. (227-299) Springer Verlag, New York, NY.

Hernández Rojas, D., López Barrera, F. \& Bonilla Moheno, M. (2017). Análisis preliminar de la dinámica de uso de suelo asociada al cultivo palma de aceite (Elaris guincensis) en México. Agrociencia 52: 875-893.

Instituto Nacional de Estadística y Censos. (2015). VI Censo Nacional Agropecuario. Atlas Estadístico Agropecuario / Instituto Nacional de Estadística y Censos. -- 1 ed. --San José. Costa Rica.

Instituto Nacional de Estadística y Censos. (2018). Encuesta Nacional Agropecuario. Recuperado de http://www.inec.go.cr/content/ encuesta-nacional-agropecuaria-publicacion-de-cultivos-2018.

Jansen, L. y Di Gregorio, A. (2002): "Parametric land cover and land-use classifications as tools for environmental change detection", Agriculture, Ecosystems \& Environment, 91, (1-3), 89-101.

Lambin E.F., Geist H.J. \& Lepers, E. (2003). Dynamics of land-use and land-cover change in tropical regions. Annual Review of Environment and Resources 28: 205-241. 
Lausch, A y Herzog, F. (2002). Applicability of landscape metrics for the monitoring of landscape change: issues of scale, resolution and interpretability. Ecological Indicators, 2, 1-2, 3-16.

Lucke, O. (1986). Escalas y niveles de detalle. Documento del curso de planificación del uso de la tierra. INFORAT, Centro Agronómico Tropical de Investigación y Enseñanza. Turrialba, Costa Rica.

Lucke, O. (1986). Consideraciones básicas sobre la aplicación de metodologías de análisis en la planificación del uso de la tierra y la toma de decisiones. Turrialba, Costa Rica. CATIE. (mimeogr).

Marceau, D., Guindon, L., Bruel, M. y Marois, C. (2001). Building temporal topology in a GIS database to study the land-use changes in a rural-urban environment. Professional Geographer, 53, (4), 546-558.

Marvin Barquero (20 de noviembre de 2018). Café, palma aceitera y caña de azúcar son los cultivos con más área en Costa Rica. La Nación. Recuperado de https://www.nacion.com/ economia/agro/cafe-palma-aceitera-y-cana-de-azucar-son-los/ KS4WMY6R3ZDOJL3BJO2UWRYFHI/story/.

Ministerio de Ambiente, Energía y Telecomunicaciones. (2011). Diagnóstico sector energía de Costa Rica. VI Plan Nacional de Energía 2012-2030.

Ministerio de Agricultura y Ganadería. (2008). Plan estratégico de la cadena productiva: Palma Aceitera. Período 2008-2010. Recuperado de http://www.mag.go.cr/bibliotecavirtual/E70-4277.pdf.

Mingorance, F., Minelli, F. \& Le Du, H. (2004). El cultivo de la Palma Africana en el Chocó. Legalidad Ambiental, territorial y Derechos Humanos. Human Rights Everyhere. Diócesis de Quibdó.

Ochoa, S. y González, M. (2000). Land use and deforestation in the highlands of Chiapas, Mexico. Applied Geography, 20, 17-42.

Pan, W., Walsh, S., Bilsborrow, R., Frizzelle, B., Erlien, C. \& Baquero, F. (2004). Farm-level models of spatial patterns of land use and land cover dynamics in the Ecuadorian Amazon", Agriculture, Ecosystems \& Environment, 101, 2/3, 117-135.

Perea Álvarez, R., Mayor Salazar, J. (2014). La cartografía como instrumento de comunicación en la planificación del espacio geográfico. Entorno Geográfico N(10), 180-193. 
Perz, S. y Skole, D. (2003). "Social determinants of secondary forests in the Brazilian Amazon", Social Science Research, 32, (1), 25-61.

Pirker, J., Mosnier, A., Kraxner, F., Havlik, P. \& Obersteiner, M. (2016). What are the limits to oil palm expansion? Global Environmental Change 40(1):73-81.https://ac.els-cdn.com/S0959378016300814/1s2.0-S0959378016300814-main.pdf?_tid=bb75db78-b556-499dac49-4f7390aa8382\&acdnat $=1548692588$ dfd507792e960a53f2106c9650f2e137.

Pontius, R., Shusas, E. \& McEachern, M. (2004). Detecting important categorical land changes while accounting for persistence, Agriculture, Ecosystems \& Environment, 101, 2/3, 251- 269.

Redacción-Vivir. (2019). Noruega, primer país en prohibir aceite de palma que causa deforestación. El Espectador. Recuperado de https:// www.elespectador.com/noticias/medio-ambiente/noruega-primerpais-en-prohibir-el-aceite-de-palma-que-causa-la-deforestacion-articulo-833082.

Seto, K., Woodcock, C., Song, C., Huang. X., Lu, J., \& Kaufmann, R. (2002). Monitoring land-use change in the Pearl River Delta using Landsat TM, International Journal of Remote Sensing, 23, 10, 1985-2004.

Soto Méndez, M. (2018). Crisis de la palma aceitera oprime a productores de Costa Rica. Especial Palma al Límite. Series de Mongabay. Recuperado de https://es.mongabay.com/2018/11/ palma-de-aceite-crisis-productores-costa-rica.

Taylor, J., Brewer, T. y Bird, A. (2000). Monitoring landscape change in the National Parks of England and Wales using aerial photo interpretation and GIS, International Journal of Remote Sensing, 21, (13), 2737-2753.

Turner, M., Pearson, S., Bolstad, P. \& Wear, D. (2003). Effects of land-cover change on spatial pattern of forest communities in the Southern Appalachian Mountains (USA), Landscape Ecology, 18, (5), 449-464.

Velázquez, A., Mas, J. F., Díaz-Gallegos, J. R., Mayorga-Saucedo, R., Alcántara, P. C., Castro, R., Fernández, T., Bocco, G., Ezcurra, E. \& Palacio, J. L. (2002). Patrones y tasas de cambio de uso del suelo en México. Gaceta 62: 21-37. 
Denis Mauricio Salas-González

Changes in the area cultivated with oil palm in the canton of Osa, Puntarenas. 2014-2018 period

Vitousek, P. M., Mooney, H. A., Lubchenco, J. \& Melillo, J. M. (1997). Human domination of Earth's ecosystems. Science 277, 494-499.

Xiuwan, C. (2002). "Using remote sensing and GIS to analyse land cover change and its impacts on regional sustainable development", International Journal of Remote Sensing, 23, (1), 107-125. 
